\title{
REFLEXÕES SOBRE O USO DO MAPA CONCEITUAL NA DISCIPLINA DE HISTÓRIA
}

Maria Limal

"O nove e o significativo uso da palavra, a sua utilizaçăo como um meio para a formação de conceitos, é a causa psicológica imediata da transformaçāo radical por aue passa o processo intelectual no limiar da adolescência.

1... A Aprender a direcionar os próprios processos mentais com a ajuda de palatras ou signosé é uma parte integrante do processon na formaçäo de conceitos"

(VYGOTSKY, 1993, p. 51)

RESUMO:

Neste artigo, com o intuito de refletir sobre o conceito de avaliação formativa, a autora apresenta um relato de experiência do uso do mapa conceitual na 8". série do Ensino Fundamental (14 anos) da Escola da Vila (instituição particular sediada em São Paulo/Brasil), num curso de História do Brasil. Compõemo texto tanto a fundamentação teórica do mapa conceitual e da estratégia didática de utilização do eixo conceitual na prática do professor de História, yuanto o esforço de reflexão sobre a ação empreendido pela autora na busca da constituição de uma prática reflexiva. Ficam evidenciadas as potencialidades deste instrumento, hem como algumas das dificuldades (dos alunos e alunas e da professora) que apareceram na sala de aula durante sua aplicação.

UNITERMOS: avaliação formativa; mapa conceitual; ensino/ aprendizagem por conceitos.

\footnotetext{
I Bacharel e licenciada en História pela Universidade de São Paulo (USP); mestre em História da Educação pela Faculdade de Educação da USP; professora de História de 7" e 8" séries da Escola da Vila, em São Paulo/SP/ Brasil, sob orientação de Ivone Domingues; trahalha com formação de professores, sendo capacitadora do Centro de Estudos da Escola da Vila, em São Paulo. E-mail: maria(a vila.com.br
} 


\section{A avaliação enquanto tema central}

Freqüentemente, a avaliação no espaço escolar tem sido encarada como um momento burocrático e sem uma relação mais profunda com a prática pedagógica da professora ou do professor, ou com o processo de aprendizagem dos aprendizes. André e Passos (1997, p. 112), ao apresentarem as considerações de alguns estudos sobre esta temática, citam o estudo de Luckesi (1995) o yual afirma que a avaliação

a) tem assumido uma função essencialmente classificatória, servindo apenas para definir os alunos cue devem ser aprovados ou reprovados; b) tem confirmado a profecia auto-realizadora dos professores, ou seja, tem sido usada para reforçar as previsões feitas sobre (quem são os bons e os maus alunos; c) tem cumprido um papel disciplinador e autoritário ficando todo o poder nas mãos do professer, yue, utilizando critérios arbitrários e instrumentos fallos, define o destino escolar do aluno.

Estas mesmas autoras apontam também que a avaliação escolar baseia-se quase que exclusivamente no resultado das provas; que o erro é pouco explorado no sentido construtivo; ou mesmo que os instrumentos de avaliação (primordialmente a prova) possuem uma linguagem acadêmica, formal, muito diferenciada dos exercícios cotidianos.

Este e vários outros estudos têm delineado o papel autoritário e pouco comprometido com a aprendizagem que a avaliação assumiu em nossa sociedade.

Em contraposição a este quadro, poderíamos falar de um modelo de avaliação de tendência mais democrática, que enxerga o aluno como sujeito de sua aprendizagem, ressaltandose o seu papel informativo para o corpo docente. Para muitos teóricos este tipo de avaliação é chamado de formativa.

Para Miras e Solé (1996, p. 382), a avaliação formativa é aquela feita no decorrer do processo (contínua) e indica ao 
aluno sua situação relativa às diferentes etapas pelas quais deve passar para efetivar uma determinada aprendizagem. A mesma também indica ao professor como se desenvolve o processo de ensino e aprendizagem, ajustando-se bem à idéia de que o ensino é um processo de tomada de decisóes.

Pode-se ainda compartilhar com Hadji (2001a) a idéia de que a avaliação formativa é, primordialmente, aquela que informa o estudante sobre o seu processo de aprendizagem, permitindo-the (e também à professora e ao professor), a "remediação" dos problemas apresentados ainda durante este mesmo processo. Ela nada mais é do que "uma avaliação que quer se colocar a serviço da formação, da aprendizagem, desde o ensino fundamental até a universidade" (HADJI, 2001a, p. 9). Neste sentido, para este autor, implementar uma avaliação efetivamente formativa deve ser mais uma questão de não perder de vista os objetivos das atividades (o seu sentido) do que uma questão técnica.

A medição, neste caso, passaria a um segundo plano². Primordialmente, seria considerado o seu caráter de "instrumento de coleta de dados para análise". Uma vez analisados, estes dados delineariam um cuadro da situação do aprendiz num determinado momento de sua escolaridade, possibilitando a tomada de decisões didáticas mais pertinentes com a sua realidade.

\footnotetext{
'No que se refere a este aspecto de medição, Hadji (2001h, p. 5) faz um interessante comentário: "Não acredito que a avaliação possa tornar-se científica. Ela não será jamais uma medida. Em contrapartida, ela poleria ser rigorosa. Tem esse dever. Avaliar com rigor implica primeiramente definir de modo exato aquiloque se espera da realidade avaliativa. Se a avaliação não é freqüentemente rigorosa, é porque nós não sabemos o que esperamos dos estudantes ou da sociedade |... |. Posso cronometrar o tempo que um corredor leva para percorrer $100 \mathrm{~m}$ - é a medida, não a avaliação. Por outro lado, não posso cronometraro tempo de desenvolvimento de uma criança, o modo como ela constrói a sua aprendizagem, desenvolve suas competências. Isso não pode ser medido."
} 
É dentro destas referências teóricas e de uma preocupação especial con a temática da avaliação escolar que apresento o relato de uma experiência desenvolvida com estudantes de 14 anos, na Escola da Vila em São Paulo. Tratase da utilização do mapa conceitual encuanto instrumento de avaliação que me forneceu importantes informações sobre o processo de aprendizagem de meus alunos e alunas que serviram para a reflexão sobre a condução do ensino.

Antes de passar ao relato, é preciso delinear o que vem a ser o mapa conceitual e qual a teoria que o fundamenta para que fiçue evidenciada também a concepção que está por trás da situação ora relatida.

\section{O mapa conceitual: fundamentação teórica}

Os mapas são diagramas conceituais que enfatizam as relações (hierárquicas) entre conceitos. Foram criados na década de 70 por Joseph D. Novak (físico norte-americano) a partir da teoria da aprendizagem de David Ausubel. Novak percebeu em entrevistas clínicas (de base piagetiana) que, quando os alunos entravam nos cursos de Física, eles já traziam conceitos/ representações. Para organizar estes conceitos, surgiu o mapa conceitual.

Os criadores do mapa conceitual partem da idéia de que, na maioria das vezes, uma pessoa ao iniciar um processo de aprendizagem já traz informações sobre os conteúdos que serão abordados. A desconsideração destes conhecimentos, muitas vezes, impede que a professora (e o professor) perceba porque determinados alunos não conseguem aprender um certo conteúdo apesar de seus esforços. Além disso, desprezar este conhecimento prévio faz com que, ao não ativá-lo, o) aluno produza assimilações deformantes. 


\section{Apesar de Ausubel utilizar a palavra conceito tanto para} o conhecimento prévio do aluno, quanto para o conhecimento resultante do trabalho com o professor, cabe aqui destacar que o primeiro não poderia ser definido como conceito propriamente dito, mas apenas como noção ou representação, "metáfora do conceito"'. É com esta preocupação que Sergei Moscovici utiliza a expressão representações sociais para designar o conhecimento prévio do aluno e Vygotsky a expressão pseudoconceito.

Ao utilizar o mapa conceitual no início de um trabalho (sem ter fornecido informações sistematizadas), estamos levando em consideração o que não só Ausubel considera, mas também Vygotsky: o aluno possui uma concepção anterior, formada pela sua vivência, a qual entrará em contato com o conhecimento que se pretende que ele "aprenda". Essa importância de se mapear os conhecimentos prévios já foi apresentada por alguns autores 5 .

Dentre eles, Carretero (1997, p. 33) apresenta quatro características dos conhecimentos prévios levantadas a partir

\footnotetext{
: "Encuranto as determinidades do sentimento, da intuição, do desejo, da rontade etc., na medida em que delas se sube são chamadas em geral representuções, pode-se dizer de modo geral que a filosofia põe, no lugar das representações, pensumentos, categorias e, mais precisamente, comceitos. As representações, em geral, podem ser vistas como metáforas dos pensamentus e conceitos." (HEGEL, (3. W. F. Encichóédia das (iências Filosóficas em Compêndio (1830). A Ciência da Lógica. Trad. Paulo Meneses. Rio de Janeiro: Loyola, 1997. v. 1, p. 42)

${ }^{+}$MOSCOVI, Serge. Las representatios sociales: expose introductif in: Troiseme Rencontre Nationle Sur La Didactique de LHistoire, de la Geographie, des Sciencies Économicpues et Sociales. Actes du Colloque. Paris: INRP, 1988.

¿César Coll, em diversas ohras; alguns textos do livro O Construtivismo na sala de aula, em especial o cap. 3 - Um ponto de partida para a aprendizagem de novos conteridos: os conhecimentos prévios; Mário Carretero, principalmente em seu livro Comstruir e Ensinar - As ciências sociais e a história. Porto Alegre: Artes Médicas, 1997 (em especial no cap. 2 - construçäo do comlecimento é ensino das ciências sociais e da história); ou mesmo o próprio Vygotsky no livro Pensamento e Lingutagem.
} 
de uma série de pesquisas realizadas na área de Ciências Experimentais, quais sejam:

a) são construções pessoais. Apesar de muitas delas serem comuns a um grande número de alunos, essas idéias fazem parte da rede de conhecimento que cada indivíduo possui e, por isso, possuem um significado pessoal.

b) Essa significação parece ter uma clara influência na grande resistência mostrada pelos alunos no momento de modificar essas concepções.

c) Geralmente, são concepções bastante afastadas do conceito ou da interpretação disciplinar correta.

d) Costuma ser implícitia. Muitas delas são adquiridas a partir do conhecimento cotidiano e o indivíduo não utiliza explicitamente a sua formulação.

O mapa conceitual pode ser um instrumento eficaz para se levantar os conhecimentos prévios ${ }^{6}$. Além disso, ele pode (e deve) ser um ponto articulador no desenrolar do projeto e um instrumento de avaliação do processo de aprendizagem ao final do projeto. Ou seja, ele pode ser utilizado no processo de avaliacs. .nmativa, tanto no sentido aplicado por Miras e Solé (1996), yuante) por Hadji (2001a).

Os mapas por serem considerados representaçóes externas dos esquemas cognitivos, trazem a possibilidade de se visualizar (parcialmente, é claro) as construções conceituais que o aluno está empreendendo durante o processo de ensino/ aprendizagem.

\footnotetext{
"Existe uma séric de outras como, por exemplo, a elaboração de um índice inicial pela criança onde ela pode enumerar o que sabe e o que quer saber sobre um determinado alssunto. Uma outra seria a elaboração de hipóteses explicativas sobre quais seriam as intormaçoes necessárias para se compreender um determinado assunto ou fenômeno, on o que ela pensa sobre este fenomeno. Poder-se-ia também fornecer um questionário com perguntas ahertas ou fechadas. Enfim, há uma série de instrumentos que poderiam ser adeguados para este mapeamento.
} 
Eles podem ser usados pelos alunos para integrar, reconciliar e diferenciar conceitos. Para os professores, como instrumento de avaliação dos significados que o aluno está atribuindo ans conceitos que estão sendo trabalhados.

Ele não pode ser entendido como uma mera técnica sendo um instrumento ou meio subordinado aos objetivos pedagógico-didáticos que se tem. Por isso, ele vai depender tanto do juízo de valor da educadora ou do educador que o utiliza, quanto da complexidade que cerca o processo educativo.

O mapa, segundo Novak, é uma projeção prática da teoria da aprendizagem de Ausubel. Por trás dos mapas, está um modelo de educação:

a) centrado no alıno e não no professor;

h) que atenda ao desenvolvimento das habilidades e não se contente apenas com a repetição memorística da informação;

c) que pretenda o desenvolvimento harmônico de todas as dimensões da pessoa, não somente as intelectuais (ONTORIA et (l., 1995, p. 32).

Os mapas proporcionam um resumo esquemático do que foi aprendido e organizado de maneira hierárquica. Além disso, são instrumentos que possibilitam situações de negociação de significados entre as pessoas que os elaboram .

Os elementos fundamentais dos mapas são: o conceito, a proposição e o conectivo. Suas características próprias são: a) seleção: eles são sínteses que contém o mais significativo de uma mensagem, tema ou texto; b) impacto visual: "um bom mapa conceitual é conciso e mostra as relaçñes entre as idéias principais de um modo simples e vistoso, aproveitando a notável

\footnotetext{
¿No casso do relato de experiencia a ser apresentado, a confecção foi feita sempre $\mathrm{em}$ dupla, garantindo-se assim tanto este processo de negociação, quanto a organização inicial de todas as informações e concepções que os alunos traziam sobre os conteridos a serem trabalhados.
} 
capacidade humana para a representação visual" (NOVAK upud ONTORIA et al., 1995, p. 39).

A aplicação do mapa tem como objetivo traballar quatro aspectos básicos:

1. conexão com as idéias prévias dos alunos

2. inclusão (que conceitos são mais relevantes?) (qual é o mais inclusivo?)

3. diferenciação progressiva (processo de ampliação dos significados atribuídos aos conceitos)

4. reconciliação integradora/integrativa (processo de ampliação) dos significados dos conceitos relacionados ao conceito que se aprendeu significativamente - efeito em cadeia)

\section{A teoria de Ausubel}

Para Ausubel, térico cognitivista, uma aprendizagem é significativa cuando há uma ancoragem, na estrutura cognitiva do aluno, de uma nova informação.

Esses aspectos relevantes da estrutura cognitiva que servem de ancoradouro para a nova informação são chamados "subsunçores". [...] Na aprendizagem significativa há uma interação entre o novo conhecimento e o já existente, na qual ambos se modificam. À medida que o conhecimento prévio serve de base para a atribuição de significados à nova informação, ele também se modifica, i.e., os subsunçores vão adquirindo novos significados, se tornando mais diferenciados, mais estáveis (MOREIRA, 2000, p. 5).

No processo de aprendizagem significativa, os conceitos modificam-se (diferenciação progressiva). Atribui-se novas relações entre subsunçores que, por sua vez, atribui novos significados às relações. Esse efeito em cadeia, que transforma o significado de diversos conceitos é chamado de reconciliação integrativa. 
Na aprendizagem mecânica, diferentemente da significativa, uma pessoa não atribui significados à nova informação, armazenando-a de forma arbitrária. Desta forma, a transformação do mapa em instrumento didático tem como oljetivo, não só possibilitar ao professor uma avaliação mais fiel do yue o aluno pensa, mas também promover o maior número de aprendizagens significativas dos conteúdos trabalhados em salla de aula.

Abaixo, un quadro comparativo:

\begin{tabular}{|c|c|}
\hline Aprendizagem significativa & Aprendizagem mecânica \\
\hline Incorporaçäo sulstantiva, não arhitrária, não & Incorporaçăo não sulsstantiva, arhitrária, litetal \\
\hline $\begin{array}{l}\text { literal de nowo conhecimento à estrutura } \\
\text { congnitiva }\end{array}$ & de nowe conhecimento à estrutura cognitiva \\
\hline 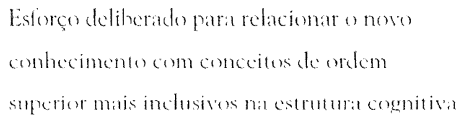 & $\begin{array}{l}\text { Nenhum esforço para integrar o nowo } \\
\text { conhecimento com conceitos existentes nat } \\
\text { estrutura cognitiva }\end{array}$ \\
\hline $\begin{array}{l}\text { Compromisso afetivo de ralacionar nowes } \\
\text { conlaceimentos com conhecimentos prérios }\end{array}$ & $\begin{array}{l}\text { Nenhum compromisso afetiro de relacionar } \\
\text { nowos conhecimentes com conhecimentos } \\
\text { prévios }\end{array}$ \\
\hline
\end{tabular}

\begin{tabular}{|c|c|c|}
\hline \multicolumn{3}{|c|}{ Representaçäo esequemática do processo de assimilaçäo segrndo Ausubel } \\
\hline$a$ & A & $A^{\prime} a^{\prime}$ \\
\hline 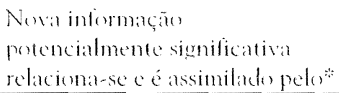 & $\begin{array}{l}\text { * conceito sulasunçor tha } \\
\text { estrutura congnitiva }\end{array}$ & Produte internacional \\
\hline
\end{tabular}

Pode-se perceher que, para o aluno atingir uma certa compreensão científica do conceito, ele deverá interagir com um bom número de informações, sistematizando-as, produzindo textos utilizando estas informações, apresentando seminários, etc ${ }^{\S}$. Ou seja, o mapa conceitual coloca-se mais como um 
instrumento de "amarração" de uma série de informações trabalhadas, tornando possível a visualização do processo de transformação conceitual pelo cuual, provavelmente, a (o) aprendiz estará passando e o qual a professora (ou o professor) estará procurando garantir. O mapa conceitual também pode servir à professora (ou ao professor) como organizador dos conceitos durante a elaboração do planejamento do curso. A visualização das relações entre os conceitos pode tornar-se um instrumento de apoio bastante interessante no planejamento das atividades. É importante ressaltar também que, no caso da Escola da Vila, a aprendizagem da técnica do mapa conceitual é colocada como um importante acordo didático. Ou seja, é fundamental que o corpo docente garanta que, ao final do Ensino Fundamental, o estudante tenha se apropriado desta técnica (entre outras), utilizando-a de forma autônoma para subsidiar suas aprendizagens (ou seja, enquanto procedimento)'.

\footnotetext{
"Estabeleço três níveis de relações referenciais para a organização das situaçōes didáticas: num primeiro nível, o ensino de fatos históricos (dados fundamentais para a reflexio que se pretende histórica); num segundo nível, o ensino dos conceitos historiográficos (atueles que os historiadores criam em suas narrativas) edos conceitos históricos (autueles que os proprios agentes-envolvidos direta ou indiretamente com os fatos históricos - criam para explicar determinados eventos); por último, o nível de construção conceitual do sujeito da aprendizagem (a compreensão e os conceitos que a(o) adolescente vai construindo). () uso de provas, trabalhos (orais ou escritos), exercícios, etc., coloca-se para os dois primeiros níveis. O mapa conceitual seria utilizado no 3". nível.
}

"Se a eyuipe de professores estiver de acordo sobre a importância da formação do estudante, deverá explicitar essa preocupação, criando um eixo de trabalho a ser incluído no planejamento de todos os educadores. A construão deste novo papel social, de estudante, pode começar a ser trabalhado, na escola, desde o início, ainda nas séries iniciais. No entanto, para que possamos de fato atingir os objetivos educacionais definidos para cada etapa da escolaridade, é necessário formularmos, com precisão, alguns acordos didáticos a serem observalos por toda a ecpuipe, com vistas a progressiva solidificaçáo de uma 


\section{O relato da situação}

A experiência ora relatada foi desenvolvida no $1^{\text {" }}$ trimestre de $2001 \mathrm{com}$ estudantes de $8^{a}$ série do Ensino Fundamental (14 anos) da Escola da Vila, instituição particular, radicada na cidade de São Paulo. É importante ressaltar que, neste relato, não se pretende apresentar apenas os "sucessos", mas os erros, as incertezas e os problemas de condução que foram encontrados pelo caminho, a fim de que a contribuição ora pretendida seja mais significativa do ponto de vista da reflexão sobre a prática cotidiana da sala de aula, buscando assim constituir o que Donald $\mathrm{A}$. Schön define como reflexão sobre a reflexão na ação ${ }^{10}$ (ALARCÃO, [19--], p. 16-17).

Para que se entenda melhor o contexto dentro do qual a experiência foi desenvolvida, torna-se necessário o fornecimento de algumas informações referenciais. No curso de História da $8^{n}$ série, são abordados conteúdos relativos à História do Brasil Colonial (início do século XIX) e Imperial"

postura de estudante consistente. Devem ser discutidos em reuniões pedagógicas aprofundando os temas e rechando-os com exemplos concretos dos encaminhamentos realizados em classe." Os acordos se dão em torno dos "procedimentos de estudo: competências e habilidades que devem ser trathalhadas na escola por todos os professores, visando o desenvolvimento do papel de estudante". Estes dividem-se em "gerais: relativos aos instrumentos, tarefas e atividades necessárias ao processo educativo"; e "lingüísticos: relativos a competências lingüísticas gerais que extrapolam os conteúdos trabalhados em Língua Portuguesa e dizem respeito a todas as disciplinas." (EQUIPE DOS (ICLOS 4 E 5 I)A ESCOLA DA VILA, 2001, p. 5).

" "Se reconstruímos mentalmente a ação para tentar analisá-la restrospectivamente, então estamos a fazer uma reflexão sobre a ação. |... |a reflexão sobre a reflexão na ação, lél o processo que leva o profissional a progredir no seu desenvolvimento e a construir a sua forma pessoal de conhecer."

"A proposta faz parte do projeto pedagógico-didático da escola (encampado pela professora) de tomar o ensino da História do Brasil o referencial para a ahordagem dos conteúdos de História Geral e da América. 
Como eixo condutor, elegeu-se os conceitos de Estado Nacional e Nação' ${ }^{\prime 2}$, por entendê-los como potencializadores tanto da concretização do projeto pedagógico-didático da escola, quanto da discussão de uma série de fatos e conceitos históricos fundamentais do século XIX relacionados à formação política brasileira.

A estruturação do curso a partir de um eixo conceitual vem na esteira de uma série de experiências e reflexões desenvolvidas no Brasil, na Argentina e na Espanha. Procurando-se associar, durante o ensino, a reflexão ao processo de construção de conhecimento, e buscando instrumentalizar os alunos com algumas ferramentas conceituais fundamentais para a análise da sociedade, alguns profissionais brasileiros vêm desenvolvendo experiências onde o fazer do historiador é reproduzido' 'na escola (CORDEIRO, 2000). Para Schmidt (1999, p. 150) o ensino-aprendizagem de História deve garantir a construção de um conjunto de ferramentas "que possam ajudar os alunos a fazerem uma análise mais profunda da realidade

12 Neste relato, por uma questão de espaço, apresentarei apenas o trabalho desenvolvido con o conceito de Estado Naciomal.

1'É importante ressaltar que, aqui, está-se pensando nesta reprodução dentro dos moldes de uma transposição didática. Sobre este conceito Jiménez e Sammarti escrevem: "Ensinar ciências implica, entre outros aspectos, estabelecer pontes entre o conbecimento, tal como expressam os cientistas através de textos, eo conlecimento yue os estudantes podem construir. Para conseguirmos é necessírio reelaborar o conhecimento dos cientistas de modo que se possa propor aus alunos nas diferentes etapas de seu processo de aprendizagem. Esta reeleboração não pode ser similar a meras simplificações sucessiras do conhecimento e constituem o campo de estudo chamado de transposiçain didática". (Trecho extraído da síntese elaborada pelo professor de Ciênciar Naturais da Escola da Vila, Marcelo Motokane, do artigo Jiménez, Marra Pilar y Sanmarti, Neus ¿QUE CIENCIA ENSENAR? OBJETIVOS Y CONTENIDOS EN LA EDUCACIÓN SECUNDÁRIA. La enseñanza y el aprendizaje de las ciencias de la naturaleza en la educación secundaria. ICE/HORSORL. Cuadernos de formación del professorado. Educación secundáriat. V(1. 9, 1997). 
social". Neste sentido, exercícios de análise de documentos históricos do mais variados tipos têm sido feitos em sala de aula, projetos de pesquisa estruturados e textos de análise produzidos por alunos e alunas. Na Escola da Vila, colocando a História do Brasil em destaque, optou-se por seguir o caminho da estruturação de projetos didáticos ${ }^{1+}$, privilegiando-se a formação de um estudante que, ao entender melhor como o historiador constrói a narrativa historiográfica, compreenda também a sua própria condição de sujeito e agente históricos (produtor de um certo tipo de conhecimento e agente de transformação social).

Isso é perfeitamente possível se consideramos que os conceitos podem ser tomados como possibilidades cognitivas (Moniot) à medida que as pessoas organizam as informações e constroem os seus conceitos de acordo com a sua inserção social e cultural. Essas possibilidades cognitivas permitem que se construa o poder conceitual - capacidade que os indivíduos têm de identificar, organizar e categorizar as informações que o) rodeiam (SCHMIDT,1999, p. 150).

Foi dentro deste referencial teórico, pedagógico-didático que a experiência que passo a relatar se desenvolveu.

It Projeto didático é uma alternativa de trabalho em sala de aula que procura superar as práticas habituais, levando em consideração que: a) o aluno deve ser o sujeito da própria aprendizagem - a organização das situaçóes escolares deve incluir as conceitualizaçóes dos alunos sobre os objetos de conhecimento e permitir suas transformações na ação sobre estes projetos, na direção dos saberes socialmente válidos. b) a transformação do objeto de conhecimento em objeto de aprendizagem deve restringir-se ao mínimo, já cule o objetivo final da aprendizagem escolar é que o aluno não pode se dissociar da versão social. Isto implica em planejar situaçóes escolares que evitem simplificaçós, distorçôes e estereótipos dos conhecimentos. c) as práticas de sala de aula devem superar uma visão estática e descontextualizada do ensino e considerar que as construçóes em relação ao conhecimento são mediadas pelo modo de aprender das crianças e de ensinar dos professores. (Fonte: documento interno da Escola da Vila intitulado "Projetos Didáticos") 
Antes de iniciar o trabalho em sala, foi feito o planejamento das secuëências didáticas. Para melhor estruturar este planejamento em termos dos conceitos a serem trabalhados, elaborei o mapa conceitual que segue.

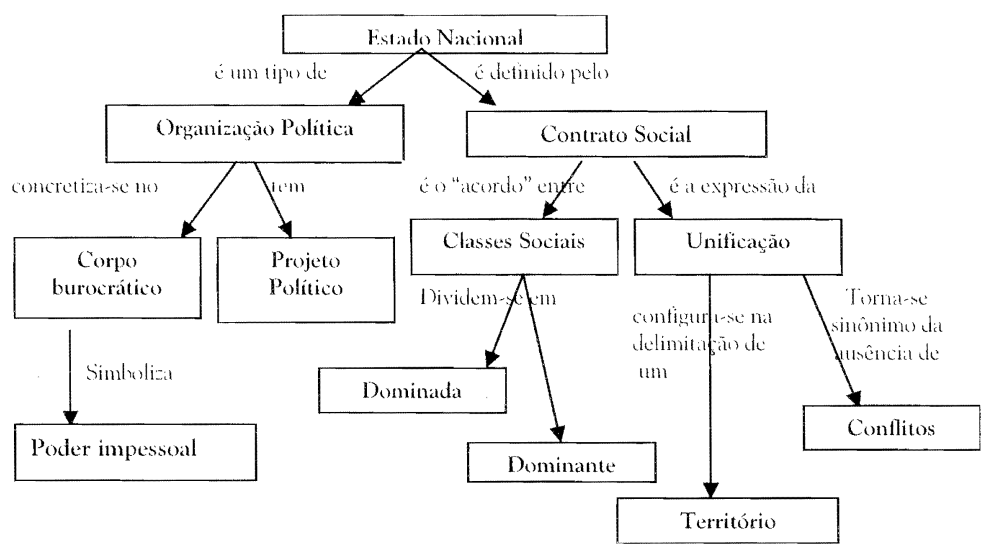

É importante ressaltar que o mapa apresentado foi feito apenas para direcionar o planejamento da professora. O mesmo não foi mostrado à aluna (ao aluno) como modelo, pois, se partimos da idéia de cue cada sujeito estabelece as relações conceituais que the são possíveis num determinado momento de sua existência, não há como expor um modelo de mapa à(ao) aprendiz. O exercício de elaboração do mapa pela professora (ou professor) foi feito pensando-se em: a) uma auto-avaliação em relação ao domínio do conceito; b) uma seleção dos conceitos que pretende priorizar no trabalho com as alunas e alunos; c) uma seleção dos conteúdos factuais que irão potencializar o trabalho de construção do conceito pelas(os) aprendizes; d) a existência de um instrumento norteador na análise dos mapas das (os) estudantes (ao analisar os mapas das(os) alunas(os), pode-se perceber melhor que conceitos é preciso trabalhar mais com eles).

Uma vez estruturado o planejamento, parti para uma 
seqüência de atividades de avaliação diagnóstica. Numa perspectiva sociocconstrutivista do ensino e da aprendizagem, a avaliação dos conhecimentos prévios dos alunos e alunas toma-se fundamental para a tomada de uma série de decisões didáticas ${ }^{15}$. Essa avaliação pode ser feita de diversas maneiras, utilizando-se variados instrumentos. No caso ora apresentado utilizou-se o mapa conceitual para registro e posterior análise.

A primeira seqüência didática ${ }^{16}$ do projeto foi iniciada por uma atividade de avaliação diagnóstical' ${ }^{17}$. Nela, os estudantes deveriam construir dois mapas conceituais: um para o conceito de Estado nacional, e outro para Nação ${ }^{18}$. As instruções foram lidas e a classe, sob coordenação da professora, debateu o yue seria um conceito, levantando e comparando exemplos.

${ }^{15}$ Segundo Schmidt (1999, p. 148), o conhecimento prévio do aluno inclui informaçñes sobte o presente e o passado, "possui uma lógica própria, não sendo, portanto, aleatório".

"Na secüîncia didática, diferentemente do projeto, não há produto final. As seçüências de atividade compóem as unidades didáticas. São unidades porque "representam un processo de ensino/aprendizagem". São didáticas poryue "constituem a unidade elementar de programação da ação pedagégica". (ZABALA, $1998)$

1: Avaliação diagnóstica ou inicial: aquela que "proporciona informações acerca das capacilades do aluno antes de iniciar um processo de ensino e aprendizagem". Proporciona também informações confiáveis sobre a hagagem dos alunos. Fundamental para a organização e seçüenciação do ensino (COLL, PALACTOS, MARCHESI, 1996).

19 O planejamento do curso previa a construção do conceito de Estado Nacional associado aro estudo dos fatos, sujeitos e outros conceitos históricos. () oljetivo maior era (e ainda é, pois o projeto estende-se por todo o ano) construir um conceito yue demonstrasse uma compreensão de que o Estado Nacional Brasileiro constituiu-se a partir do embate entre diversos projetos políticos. A idćia de se separar o conceito de Nação veio en decorrência da antecipação que fiz de que seria melhor construir um percurso em que os alunos pudessem visualizar como os sujeitos históricos estudados construíam um conceito de Nação associado ao projeto político que tinham para o Estado, constituindo assim o conceito de Estado Nacional. Isto tudo sem deixar de lado as visões que a própria historiografia construiu a partir de diferentes fontes. 
Depois desta primeira discussão, em dupla, os estudantes iniciaram a confecção do mapa pela listagem de dez conceitos que, na sua opinião, melhor definiam o conceito principal em questão. É importante ressaltar que não foi dada nenhuma aula expositiva, nem lido algum texto antes desta atividade, pois a intenção era avaliar os conhecimentos que os alunos já traziam, sua visão de mundo, suas concepções e suas hipóteses.

Durante a confecção dos mapas, a professora circulava pela sala atendendo às dúvidas, observando e fazendo anotações, que, posteriormente, foram analisadas.

A confecção do mapa do conceito de Nação foi bastante trancuuila. Os conceitos que mais apareceram foram: "população", "raça", "comunidade", "povo", "costume", "cultura" e "governo". Ou seja, nas três turmas analisadas havia uma concepção de que o conceito de Nação relacionava-se, primordialmente, à comunhão de valores, advindos de heranças culturais, excluindo-se aí a idéía de fronteiras ou delimitação espacial (elementos atribuídos, em alguns poucos mapas, ao conceito de Estado Nacional). Isto era bastante interessante e era proveniente, sem dúvida, do curso de Geografia da $7^{3}$ série, onde são estudados aspectos relacionados ao conceito de Fronteira. O curioso é que entrava um componente da política expressado pelo conceito de "governo", colocado na grande maioria dos mapas. Este me pareceu ser o caminho através do qual eu poderia promover a construção do conceito de Estado Nacional e também a ponte que possibilitaria a compreensão do conceito de Nação enquanto projeto político.

Uma dificuldade começou a aparecer quando os alunos foram elaborar o mapa com o conceito de Estado Nacional. As falas foram uníssonas: "Não sei nada!", "não consigo fazer", "não encontro conceitos". ". Ao perceber que a dificuldade era geral, encaminhei da seguinte forma: disse a eles que, para 
elaborar a lista, pensassem os conceitos em separado - alguns para Estado, outros para Nacional-, mas que, na hora de montar o mapa, que fizessem isto com as palavras "Estado Nacional" juntas, ocupando o mesmo quadrado. Isto parece ter aliviado as tensões na hora e todas as duplas conseguiram elaborar seus mapas.

Durante a elahoração dos mapas fiz uma série de anotações na planilha de observação que havia preparado. Nesta planilha anotei dados sobre: os conceitos que apareceram, a integração entre os membros da dupla; elementos das concepções da dupla; questões que fizeram; principais relações estahelecidas e observações/encaminhamentos. Apresento dois mapas do conceito de Estado Nacional elaborados por alunas a partir dos quais exemplificarei a análise feita das produçôes:

Mapa 1 - Nina e Ana B. 8 B - Fev./2001.

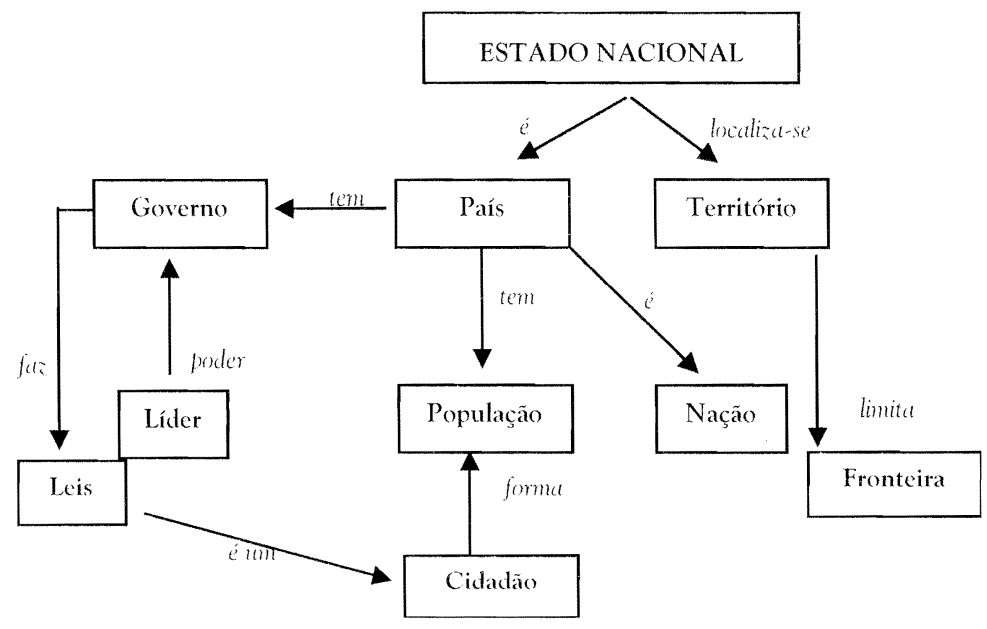

1" Neste momento, percehi a dificuldade que o conceito colociva para as turmas. Ficou evidente que era preciso investigar mais para ver se o mesmo era apropriado para o trabalho com esta faixa etária ou se eu não estava utilizando as estratégias didáticas de maneira adecuada àquele grupo. 
Mapa 2 - Maria Eugênịa e Nira 8a C - Fev./2001.

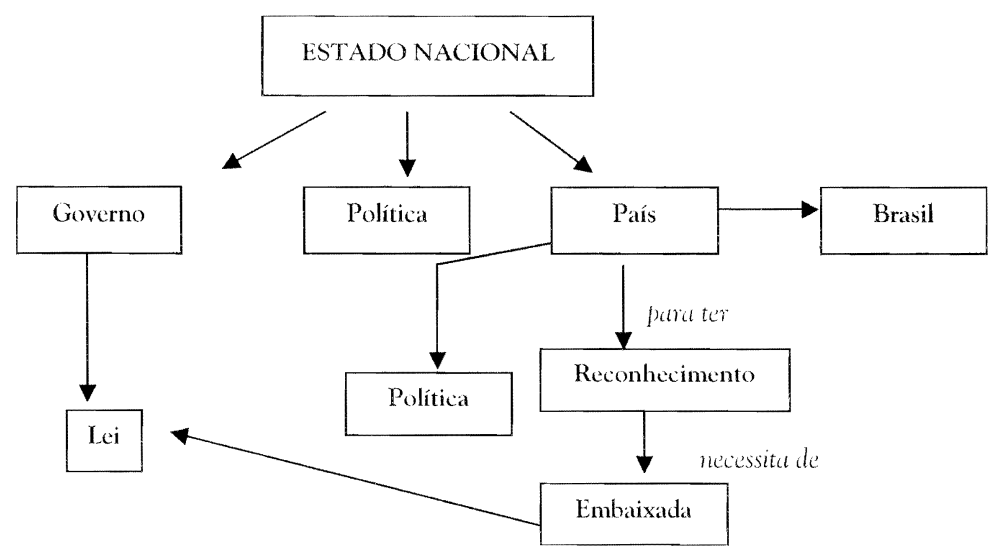

Tanto no mapa número 1 , quanto no número dois, os conceitos que relacionam Estado Nacional a uma temática da política estão presentes, indicando que as alunas em questão já têm construídos tanto o conceito de política, quanto o de Estado ${ }^{20}$. Os principais problemas observados referem-se à construção do mapa en si. As alunas do mapa número 1 conseguiram colocar conectivos em todas as relações, demonstrando um esforço de reflexão sobre todas as relações conceituais que estabeleceram. No mapa número 2, parece que as alunas tiveram dificuldades em pensar as relações, pois quase não há conectivos. Outro elemento que aponta a dificuldade

2I Isto era, de certa forma, esperado, uma vez que, no trabalho com o conceito de Igreja católica nos séculos XVI e XVII (realizado na 7". série), trabalhamos o conceito de Estado (relacionado ao Estado português) e de formação das Monarquias Nacionais para entender o Padroado. O que este estudo me mostrou foi yue eu preciso sistematizar melhor este conceito na 7". série, introduzindo a leitura de algum filósofo iluminista ou texto teórico sobre a temática do Estado nacional moderno, fornecendo assim elementos conceituais dentro de um ambiente bastante significativo. 
das alunas é a natureza dos conectivos que utilizaram. "Para ter" e "necessita de" são dois conectivos que estabelecem uma relação causal e não de definição. Nesse sentido, seu mapa assemelha-se mais a um esquema ${ }^{21}$. No esquema, normalmente organiza-se informaçóes que se consegue retirar de um texto que está lendo ou o se que sabe sobre algum assunto. Este instrumento ajuda na hora de recuperar as informações principais que precisam ser guardadas para futuras atividades. No mapa conceitual normalmente só são colocados conceitos. Haverá poucos (ou quase nenhum) exemplos, nomes de pessoas, datas, etc. O que interessa mais são as características, a natureza do conceito em questão. No mapa número 1 esta confusão também aparece. Elas utilizam "localiza-se", "limita", "faz", "forma", deixando a relação "governo/líder" indefinida ao colocar um conceito ("poder") como conectivo.

A intervenção da professora deu-se de forma a fazê-las refletir sobre a natureza destes conectivos: o que indicam?

"O esquema é uma organização do conhecimento em unidades ou agrupamentos holísticos, ou seja, que quando se ativa um dos exemplos, ativa-se todo o resto. É uma segmentação das representações holísticas em subnidades interrelacionadas

Estrutura de forma serial e hierírquica as representaçōes. Quanto aos processos de memorização ele: codifica a informação a partir de seus quatro processos básicos: seleção, ahstração, interpretação e integração. Busca-se a informação mais relevantes para a criação de esquemas também mais relevantes. Para isso, é necessário um processo de seleção da informação. O passo seguinte é a extração dos elementos mais significativos mediante o processo de abstração. Segue um processo de interpretação com a intenção de favorecer a compreensão da informação ou para fazer inferências de acordo com a idéia que o indivíduo tinha. Por fim, o processo de integração consistente na criação de um novo esquema ou na modificação de algum que já existe. Com relação à recuperação) de informaçnes: facilita a recuperação da informação relevante cuuando se trata de compreender um objeto ou uma situação que tenha certa relação com um esquema determinado. (trecho extraído de Sierra y Carretero (1990) e citado em Ontoriact al. (1995)) 
Quando defino algo ou alguém, que expressões utilizo? "Leva a", "localiza-se", etc. referem-se a que tipo de situação?

Outro elemento interessante que podemos observar é que, para as alunas do mapa número 1, há uma melhor clareza do que é um conceito, pois há conectivos que indicam isto: "é", "é um", "tem". O trabalho com estas alunas foi mais no sentido de diversificarem estes conectivos, utilizando termos mais significativos ou elaborando frases melhor estruturadas, saindo do simples "é" e passando talvez para "é definido por"; "tem um caráter", "simboliza".

Os resultados da intervenção podem ser observados no 2". mapa, confeccionado algumas semanas depois, após a leitura de um texto e aula expositiva.

\section{Depois do $1^{\circ}$ mapa, o replanejamento}

Algumas das dificuldades apresentadas por alunos e alunas durante a atividade foram fundamentais para tomar algumas decisões didáticas na continuidade do trabalho.

Originalmente, eu havia planejado a seguinte seqüência: entregar um formulário onde eles registrariam as suposiçóes que tinham sobre quando havia se dado a formação do Estado Nacional Brasileiro; em seguida, introduzir o documento histórico ${ }^{2-}$, iniciar a análise do período inicial do século XIX, apresentar as interpretações historiográficas que consideram este momento como fundamental para o processo de Independência e o período constituinte da estrutura política e econômica do Estado Nacional Brasileiro ${ }^{23}$. Para fechar esta

\footnotetext{
$\therefore$ Trata-se aqui do decreto de Abertura dos Portos, escrito por D. Joào, prínciperegente de Portugal, em 1808.
} 
unidade didática, foi pensada a reelaboração do primeiro mapa conceitual, a fim de que eu averiguasse como eles estavam mobilizando a discussão em termos conceituais e, também, para propiciar momentos em que eles pensassem sobre o seu próprio processo de aprendizagem.

Com a dificuldade detectada na elaboração do primeiro mapa, resolvi então introduzir uma atividade depois do levantamento de suposições: eles leram um texto que continha a história do surgimento do Estado Nacional, apontando os elementos que o constituíram. A este texto, acrescentei uma aula expositiva motivada pelas dúvidas que o mesmo gerara. Depois disto, convideios a reelaborar o primeiro mapa, produzindo já o segundo.

O que se pôde observar então foi uma mudança de atitude dos alunos ${ }^{24}$. Mostraram-se mais seguros para falar do conceito

\footnotetext{
$\because$ A estruturação desta unidade didática levouem consideração que "si queremos dotar a los alumnos de un mejor pensamiento histórico es necesario que les proporcionemos no sólo habilidades y estrategias que les permitan ejercer un pensamiento crítico y autónomo - cosa que ya parece haher sido admitida por torlas las personas preocupadas por este tipo de problemas - sino también unas teorías o modelos conceptuales que les permitan interpretar esse tipo de situaciones de un modo más próximo al conocimiento experto" (POZO, ASEN(IO), CARRETERO, 1989, p. 214).

"No curso da 7 série, onde o conceito central do 1 "trimestre é o de "Igreja Católica", o desequilíbrio provocado pelas dúvidas e incertezas do que vinha a ser o conceito foi muito mais "suportável" para os alumos do que aquele que havia provocado o trabalho com a 8 série. Neste sentido, não houve a necessidade da introdução de um texto de enfoque mais conceitual e da aula expositiva. Passei diretamente para o trabalho com os conteúdos factuais e conceituais que havia planejado. No caso da 8: série, a mudança de estratégia atendeu à necessidade de se colocar o material didático num nível de apreensão possivel para os alunos, permitindo assim cue a motivação não se perdesse. (Entenda-se aqui por motivaçáa como o entrecruzamento entre compreensão cos aspectos afetivo-emocionais (CARRETERO) 1996, p. 15). Ou seja, procurouse ajustar os desafios propostos, mantendo-os dentro da Zona de Desenvolvimento Proximal (ZLP) dos alunos. (Sohre o conceito de ZDP, veja-se ()liveira (1993) e Vygotsky (1993).)
}

História \& Ensino, Londrina, v. 7, p. 167-196, out. 2001 
de Estado Nacional, claro que não em sua plenitude, mas indicando já a incorporação de alguns elementos que poderiam ser essenciais a sua compreensão. Puderam iniciar um processo de ancorarem com maior clareza dos conceitos que haviam ativado na primeira atividade. Esta situação modificou a minhar primeira interpretação sobre as possibilidades de ter escolhido um conceito de complexidade muito alta para a série. Surgiram agora novos problemas que possibilitaram que eu enxergasse outras questões que estavam por trás do uso do mapa conceitual. Abaixo, reproduzo o $2^{\underline{ }}$ mapa elaborado pelas duplas citadas anteriormente.

20. mapa conceitual - Nina e Ana B. 89 B - Mar./2001

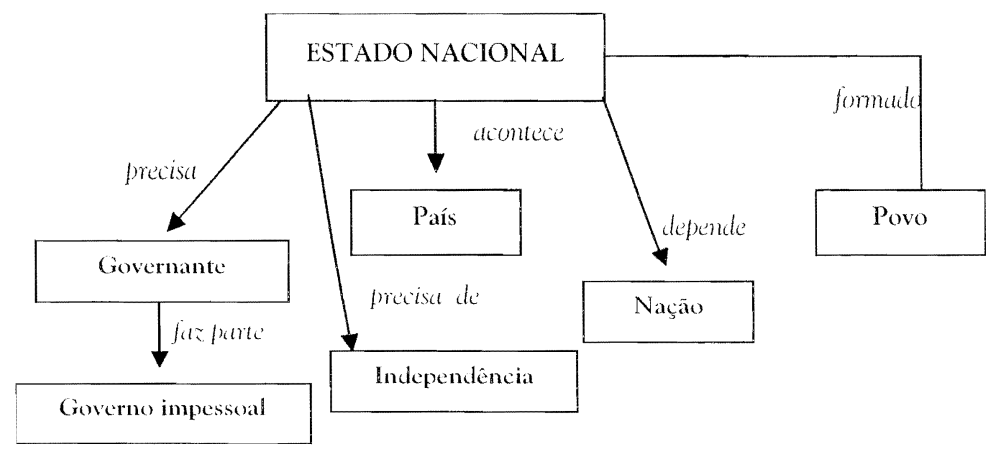


2". mapa conceitual: Maria Eugênia e Nira 8 ${ }^{\mathrm{a}}$ C - Mar./2001

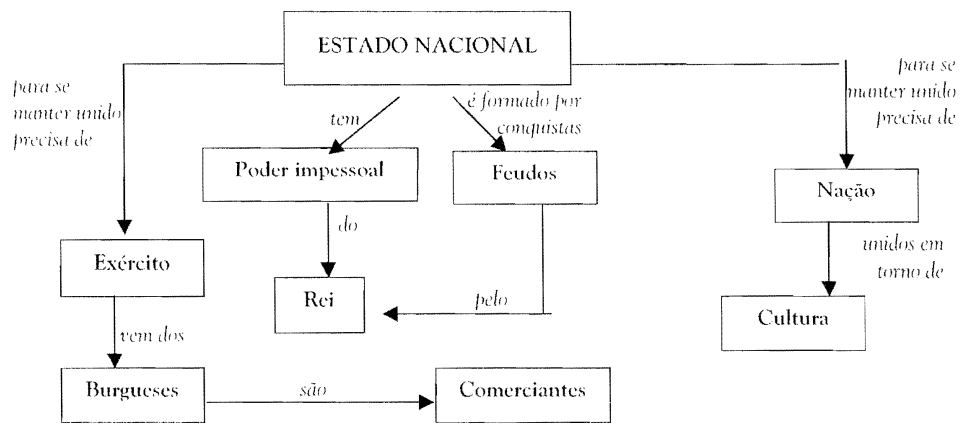

Analisando estes mapas, podemos perceber que as alunas conseguiram aprender um pouco mais sobre o que vem a ser o mapa conceitual, ampliando assim a sua capacidade de operar conceitos. Neste processo de aprendizagem, podemos detectar as dificuldades que ainda persistem. No mapa da dupla Ana B. e Nina ( $8^{a}$. b), percebemos que houve dificuldade em hierarquizar os conceitos. Na concepção delas, tudo se liga diretamente ao conceito de "Estado Nacional". Ao contrário do 1". mapa que elas confeccionaram, neste colocaram um número maior de conectivos de característica causal. Além disso, houve a mudança dos conceitos que compõem o mapa. Estes elementos associados podem indicar à professora que: a) as informações introduzidas pelo texto e pelas aulas expositivas promoveram um desequilíbrio na construção conceitual inicial das duas alunas; h) elas estão buscando recuperar o equilíbrio cognitivo ao colocar todos os conceitos ligados a "Estado Naciomal" Esta estratégia demonstra que elas estão tentando resolver algo que não estão conseguindo fazer: hierarquizar os conceitos. 
No mapa da dupla Maria Eugênia e Nira percebemos que o conceito de mapa conceitual ainda não foi assimilado. As alunas estruturaram-no como um esquema, privilegiando conectivos de relação causal, típicos nos esquemas e organogramas. Nestas alunas o processo de compreensão do que vem a ser um conceito e como articulá-lo a outros provavelmente levará mais tempo do que o da outra dupla analisada. No entanto, pode-se perceber que ele ocorrerá (dependendo da intervenção da professora), pois já se observa a presença de conectivos que expressam relações de caracterização como "tem" e "são".

\section{Potencialidades didáticas do mapa}

A análise acima apresentada demonstra a série de possibilidades que o mapa conceitual oferece tanto à professora e ao professor, quanto às(aos) aprendizes. Ou seja, este instrumento é extremamente potencial tanto para o ensino, quanto para a aprendizagem.

Como exemplo destas potencialidades, abaixo, transcrevo um dos diálogos travados entre professora e estudantes que foram gravados durante a reelaboração do primeiro mapa e a análise posterior que o mesmo propiciou:

- Renato e Guilherme (8" série C)

- (Guilherme) Eu queria saber se o Estado Nacional tem só um governante...

- (Profa.) Se o Estado Nacional tem só um governante? () que vocês acham? Dêem uma olhada no texto. Verifiquem... Como será que se chama... O texto dá um nome para o governante...

- (Guilherme) chefe de Estado. 
- (Profa.) Isto, o chefe de Estado! Vocês viram que "Estado" está escrito com letra maiúscula, certo?

- (Renato) Mas tem que ser um, por exemplo, um rei ou uma pessoa eleita pelo povo? Não poderia ser um tipo de congresso mandando?

- (Profa.) Poderia ser no caso de um sistema parlamentarista, onde são eleitos diversos congressistas para governar.

- (Guilherme) Está errado colocar no mapa que é só o rei...?

- (Profa) O que você acha?

- (Guilherme) Bem, se pode haver um sistema parlamentarista...

- (Profa.) Você pode colocar aquilo que o texto fala e acrescentar esta informação que vocês estão trazendo agora, que, no caso, é um outro tipo de organização do Estado.

Podem ser percebidos diversos elementos nesta situação: ambos mobilizaram conhecimentos anteriores na análise do novo conceito que se colocava. Juntos, conseguiram formular questões para a professora que apontaram na construção deste conceito. A professora ofereceu a ajuda necessária e ambos agregaram uma nova informação a uma que já sabiam. Pode-se dizer que houve aqui uma aprendizagem significativa, promovendo-se uma reconciliação integrativa.

Um outro aspecto bastante interessante nessa situação é a percepção de que a construção se deu de forma social, numa situação comunicativa. Neste sentido, podemos dizer que toda a situação foi trabalhada dentro da Zona de Desenvolvimento Proximal dos alunos, entendendo-se a mesma como "a diferença existente entre aquilo que um aluno pode aprender sozinho e aquilo que ele aprende com a ajuda de outros", sendo este "outros" o seu colega ou a professora (GRUPO DE FORMAÇÃO LE PROFESSORES ALFABETIZADORES, 2001, p. 28). 
Os elementos apontados acima demonstram a importância que este tipo de atividade tem não só para a avaliação, mas para o próprio processo de aprendizagem dos alunos. A professora pôde atender a uma necessidade específica, individual, e promover uma aprendizagem que, num contexto de permanente desconsideração destas interações, não seria possível. Pôde também chamar a atenção para aspectos que, numa aula expositiva ou numa atividade coletiva, poderiam passar desapercebidos.

Ao utilizar o mapa conceitual, alunos e alunos foram colocados em diversas situações potenciais para a promoção da aprendizagem. Ou seja, a diversidade de estratégias de trabalho dentro da sala amplia as possibilidades de assimilação dos conteúdos ${ }^{25}$.

\section{As maiores dificuldades observadas}

A dificuldade mais comum de alunas e alunos mapeada durante as duas atividades relatadas foi a elaboração dos conectivos. E esta não é uma dificuldade gratuita. O conectivo é o elemento mais difícil do mapa e o mais importante também. É através dele que se pode perceber o nível de elaboração conceitual que o sujeito da aprendizagem se encontra. É ele que nos possibilita verificar se a(o) aprendiz está conseguindo construir conceitos. Por isso, o trabalho da professora/professor deve ser no sentido de insistir para que as alunas e alunos o façam.

Como apontado anteriormente, as (os) estudantes tiveram dificuldades em levantar hipóteses sobre o que vinha a ser

\footnotetext{
25 "Conterulos" anui entendidos dentro da tipologia yue considera os seus diversos tipos no yue se refere à estruturação do planejamento: factuais, conceituais, procedimentais e atitudinais
} 
"Estado Nacional". Isto pode acontecer e deve ser encarado pela professora/professor como um desafio no sentido de criar condições para que a aluna e o aluno construam o conceito a partir do instrumental que tiverem.

As maiores dificuldades da professora giraram em torno do ensino do que vinha a ser o mapa conceitual e o que ele deveria conter. Possibilitar que os alunos construíssem o conceito de "conceito" foi um dos desafios. O outro, foi possibilitar que eles superassem a idéia do mapa enquanto um "esquema". Percebi que tanto a compreensão do que deveria compor o mapa - ou seja, o que era efetivamente o mapa - quanto entender o que é um conceito faziam parte do aprendizado. Ou seja, fazê-los pensar por conceitos era um desafio que estava ocorrendo em diversos níveis: na compreensão do que era o mapa; do que era um conceito; o que eram os conceitos de Estado Nacional e Nação; e de como todo o conteúdo factual estudado articulava-se aos dois conceitos principais. Eram vários os desafios a serem vencidos e, por isso, só poderiam ocorrer gradualmente. Por isso o trabalho com estes conceitos irá até o final do ano de 2001.26

Uma outra dificuldade que se apresentou foi possibilitar que os alunos entendessem que o mapa não podia conter conectivos que indicassem relações de natureza causal, pois isto não definia a essência do conceito. Dois conectivos usados freqüentemente eram "leva a" e "gera" (além de "precisa de"). Minha estratégia sempre foi a de tentar discutir um pouco mais o que deveria conter o mapa (a definição, a essência do conceito) e, na maioria dos casos, solicitar que eles não utilizassem nenhuma expressão que indicasse a idéia de causalidade.

\footnotetext{
2" Isto não aconteceu no caso da 7". série, onde o conceito de "Igrcja Católica" ofereceu menos desafios connitivos aos alunos.
} 


\section{Considerações acerca do uso do mapa como instrumento de avaliação}

Considerando-se que o erro pode levar o sujeito a modificar seus esquemas (LA TALLE,1997, p. 37), a atividade de revisão do mapa num período posterior a um processo de ensino, tornase extremamente rica, valorizando o erro e relativizando-o. Ao observar seu erro, várias vezes durante o ano, o aluno e a aluna fazem-no como um observável, ou seja, ambos têm acesso à qualidade do seu erro, cada vez mais dotados do instrumental necessário para analisá-lo e superá-lo (LA TALLE,1997, p. 36).

Neste sentido, o mapa conceitual pode se tornar um importante instrumento de avaliação dentro de uma perspectiva formativa, pois ele pode cumprir uma série de quesitos: fornecer dados para orientar a ação daquele que a aplica; colocar-se a serviço da aprendizagem, e servir de fonte de informação para a professora e o professor sobre as principais dificuldades encontradas pelos alunos (HADJI, 2001, p. 4). Enfim, ele possibilita uma melhor adequação do ensino ao processo de aprendizagem.

É interessante observar que o mapa evidencia o caráter descartável da nota, enquanto "medidor" da aprendizagem e enquanto fornecedor de informações para a aluna e o aluno sobre o seu processo de aprendizagem. Como não há "mapa certo" ou "mapa errado", o que se faz é analisar a produção do aluno, indicando-the (e à professora/professor) o que precisa ser retomado e o que já foi aprendido. Ou seja, observa-se o processo de aprendizagem, a eficácia do ensino e dialoga-se com a(o) aprendiz sobre este processo.

Enfim, avalia-se efetivamente. 


\section{Bibliografia}

ALARCÃO, I. (Org.). Formaçũo reflexiva de professores - Estratégicas de supervisüo. Porto: Porto Editora, [19--].

ANDRÉ, M. E. D. A.; PASSOS, L. F. Para além do fracasso escolar: uma redefinição das práticas avaliatitias. In: AQUINO, J. G. (Org.). Erro e fracasso na escola: alternativas teóricas. São Paulo: Summus, 1997.

CARRETERO, M. Constnuire ensinur - as Ciências Experimentais, as Ciêncius Socicis e a Históric. São Paulo: CEEV-apostila do Seminário Internacional (20 e 21.09). (mimeo), 1996.

COLL, C.; PALACIOS, J.; MARCHESI, A. Desenvolvimento psicológico e educaçũo. Porto Alegre: Artes Médicas, 1996. v. 2.

CORDEIRO, J. F. P. A História no centro do debate: as propostus de renoricçũo do ensino de História nas décudas de setenta e sitenta. Araraquara: FCL/ Lahoratório Editorial/UNESP; São Paulo: Cultura Acadêmica Editora, 2000.

Equipe dos ciclos 4 e 5 da Escola da Vila Quundo eles crescem. São Paulo: CEEV. Documento interno, 2001. (mimeo)

(GRUPO DE FORMAÇÃO DE PROFESSORES ALFABETIZADORES. São Paulo: CEEV (Centro de Estudos da Escola da Vila), apostila do curso, 2001.(mimeo)

HADJI, C. Averaliução desmistificada. Porto Alegre: Artes Médicas, 2001 1. HADJI, C. Avaliar para melhor formar. Revista Educuçũo, São Paulo, n. 237 , jan. $2001 \mathrm{~b}$.

LA TALLE, Y. de. O erro na perspectiva piagetiana. In: AQUINO, J. G. (Org.). Erro e fracasso na escola: alternativas teíricas. São Paulo: Summus Editorial, 1997.

MIRAS, M. ; SOLÉ, I. A av'aliação da aprendizagem e a avaliação no processo de ensino e aprendizagem. In: COLL, C.; PALACIOS, J.; MARCHESI, A. Desenvolvimento psicológico e educução. Porto Alegre: Artes Médicas, 1996. v. 2.

MOREIRA, M. A.; BUCHWEITZ, B. Mapas Conceituais-instmumentos didáticos de crécliação e de análise de currículo. São Paulo: Moraes, 1987. 
, M. A. Mapas conceituais e aprendizagem significativa. São Paulo: Congresso do (jrupo, 2000. (mimeo.)

OLIVEIRA, M. K. Vygotsky - Aprendizado e desenvolvimento um processo sócio-histórico. São Paulo: Scipione, 1993.

ONTORIA, A. et al. Mapas conceptuales-una tecnica para aprender. Madrid: Narcea, 1995.

POZO, J. I.; ASENSIO, M.; CARRETERO, M. Modelos de aprendizajeenseñanza de la História. In: La enseñanza de las Ciencias Sociales. Madrid: Visor, 1989.

SCHMIDT, M. A. Construindo conceitos no ensino de História: "A captura lógica" da realidade social. História e Ensino, Londrina, v. 5, p. 147-63, out. 1999.

VYGOTSKY, L. S. Pensamento e linguagem. São Pauk: Martins Fontes, 1993.

ZABALA, A. A prítica edncutiva. Porto Alegre: Artes Médicas, 1998.

ABSTRACT:

In this article, with the aim of thinking about the concept of formative evaluation, the author presents a report of her experience on using the conceptual map on an $8^{\text {th }}$ grade class (14 years old students) at Escola da Vila (private school located in São Paulo/ Brasil), as part of a Brazilian History course. The text is composed by both the theoretical foundation of the conceptual map and the didactic strategy of using the concept axle on the History teacher practice, and the exercise of reflecting about the action taken by the author on searching a reflexive practice. The potentialities of this instrument are cleared as well as some of the difficulties (both from the students and the teacher) that came up in the classroom during its practice.

KEY WORDS: formative evaluation; conceptual map; learning/teaching through concepts. 